\title{
Inflammatory Myofibroblastic Tumor of the Colon with an Unusual Presentation of Intestinal Intussusception
}

\author{
Yeliz Çağan Appak ${ }^{1}$ Gülseren Evirgen Sahin ${ }^{1}$ Semin Ayhann ${ }^{2}$ Can Taneli ${ }^{3}$ Erhun Kasırga ${ }^{1}$ \\ ${ }^{1}$ Department of Pediatric Gastroenterology, Faculty of Medicine, Celal \\ Address for correspondence Yeliz Çağan Appak, MD, Department of \\ Pediatric Gastroenterology, Faculty of Medicine, Celal Bayar University, \\ Bayar University, Manisa, Turkey \\ 2 Department of Pathology, Faculty of Medicine, Celal Bayar University, \\ Uncubozköy, Manisa 45030, Turkey (e-mail: yelizcagan@yahoo.com). \\ Manisa, Turkey \\ ${ }^{3}$ Department of Pediatric Surgery, Faculty of Medicine, Celal Bayar \\ University, Manisa, Turkey \\ Eur J Pediatr Surg Rep 2014;2:54-57.
}
Abstract
Keywords
- inflammatory myofibroblastic tumor
- intussusception
- childhood

Inflammatory myfibroblastic tumor (IMT), also known as inflammatory pseudotumor is unusual, benign solid tumor. This tumor is commonly reported in the lungs but can be present in extrapulmonary sites as well. We present the case of a 7-year-old girl with IMT in an unusual location. The patient was admitted with abdominal pain, and ultrasound showed a solid mass in the abdomen. She was operated and colocolic intussusception secondary to a mass was found. Histologic evaluation of mass revealed IMT.

\section{Introduction}

Inflammatory myfibroblastic tumor (IMT) is rare and may be grouped within the family of fibroinflammatory disorders. This tumor affects predominantly children and young adults, but patients of any age and sex can be affected. ${ }^{1}$ Its clinical symptoms are also diverse according to the location of the lesion. A mass, fever, weight loss, malaise, pain, and sitespecific symptoms were the most common presenting complaints or manifestations. ${ }^{1}$ However, IMT seldom presents in the colon and intussusception is a rare complication of this tumor. We document this unusual presentation of IMT in this case report. There are few pediatric IMT cases in the literature such as our patient. Because of this presentation, IMT should be considered in patients with colocolic intussusception.

\section{Case Report}

A 7-year-old girl was admitted with abdominal pain to our center. On physical examination, the patient had a palpable mass in the midline of the abdomen. Abdominal ultrasound showed a solid mass which was $6 \times 5 \times 4 \mathrm{~cm}$, hypervascular and partly calcified areas in the center. The white blood cell count was $7,300 / \mathrm{mm}^{3}$, hemoglobin $6.8 \mathrm{~g} / \mathrm{dL}$, platelet count $554,000 / \mathrm{mm}^{3}$, C-reactive protein $154 \mathrm{mg} / \mathrm{L}$, erythrocyte sedimentation rate $27 \mathrm{~mm} / \mathrm{h}$, biochemical values were normal. Immunoglobulin (Ig) A was $222 \mathrm{mg} / \mathrm{dL}$ (normal, 70-312 mg/dL), Ig M was $114 \mathrm{mg} / \mathrm{dL}$ (normal, 56-352 mg/dL), IgG was 1,030 mg/dL (normal, 639-1,349 mg/dL). Patient was operated and colocolic intussusception was found. Involved segment was beginning from $4 \mathrm{~cm}$ distal of the ileocecal valve and including a polipoid mass. Resection of the involved segment of the ascending colon was done with end-to-end anastomosis.

The polipoid mass was $5.5 \times 4.5 \times 3.5 \mathrm{~cm}$ wide, sessile, sticking to the mucosa with an area of $3.5 \times 3 \mathrm{~cm}$ macroscopically. The tumor covered the bowel wall at full thickness (-Fig. 1). The tumor composed of fibroblast/myofibroblastlike cells which were spindle, vesicular nuclei, some places with prominent nucleoli, and unclear boundaries of the cytoplasm. The tumor cells contained prominent mixed inflammatory cells including numerous plasma cells (-Fig. 2). Immunohistochemistry was positive for actin and negative for CD117, desmin, S-100, pancytokeratin, bcl-2, and
License terms

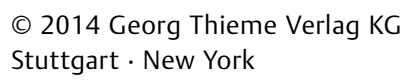
Stuttgart · New York

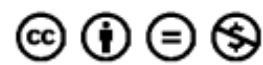

October 21, 2013 accepted after revision December 16, 2013 published online April 4, 2014

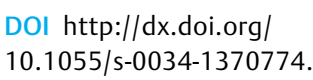




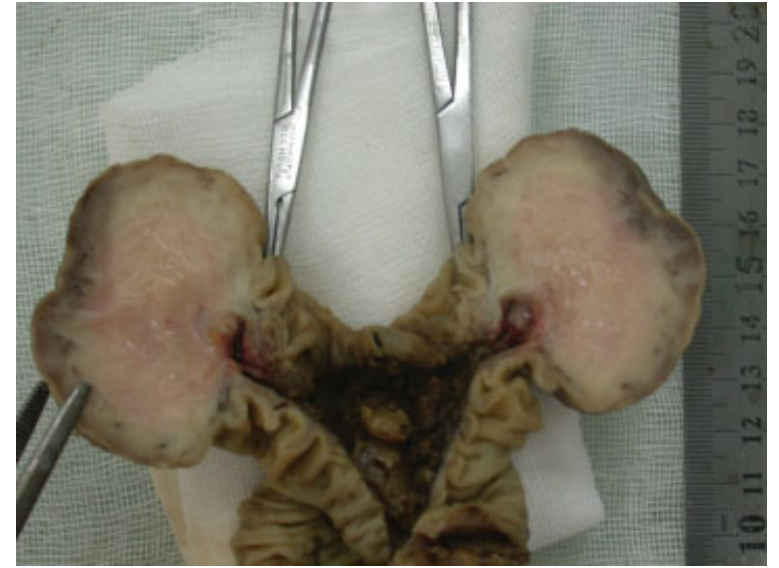

Fig. 1 Macroscopic view of polipoid mass emanating from bowel wall. The surface seems ulcerated and cut surface exhibits solid, white, fibrous texture.

anaplastic lymphoma kinase (ALK) ( - Fig. 3). Tumor cells were negative for CD34. Evaluation of mass revealed IMT of colon.

After surgery, laboratory values of the patient improved dramatically. One year later, the patient was evaluated through the colonoscopy. There were two polypoid structures on anastomosis line and their pathological examinations were nonspecific. We are following up the patient with biochemical examinations and abdominal scanning closely for tumor recurrence.

\section{Discussion}

IMT was first described in 1937 as a primary lung tumor. The tumor consists of the proliferation of fibroblastic-myofibroblastic cells admixed with inflammatory infiltrate. ${ }^{1}$ Independent of the location, IMT is more common in children and young adults, but patients of any age and sex can be affected. ${ }^{1}$ IMT is rare and may be grouped within the family of fibroinflammatory disorders. This benign tumor typically resides in

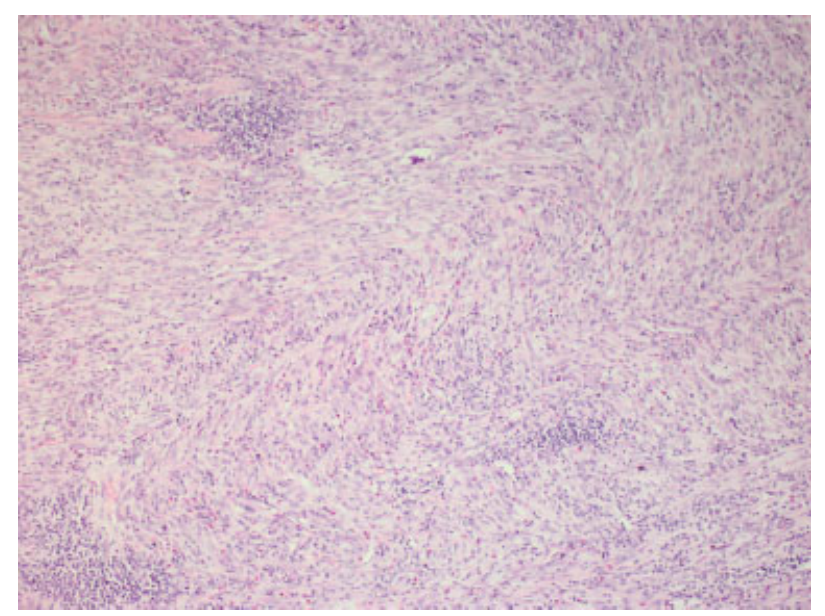

Fig. 2 A fascicular pattern in which the lesional spindle cells were arranged in moderately cellular with intersecting fascicles with a heavy infiltrate of lymphoplasmacytic cells in the background. Their nuclei were elongated with occasional small nucleoli (hematoxylin and eosin stain; $\times 10)$.

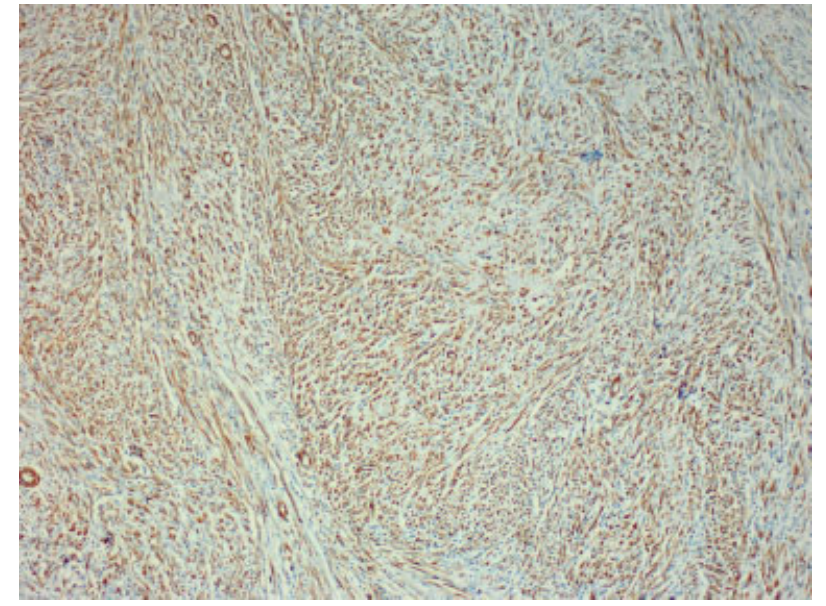

Fig. 3 The expression of smooth muscle actin by immunohistochemistry in the spindle cells (antismooth muscle actin; $\times 10$ ).

the lung; however, multiple extrapulmonary manifestations have been reported. ${ }^{2,3}$ Sites of extrapulmonary IMT may include the upper respiratory tract, mesentery/omentum, genitourinary tract, gastrointestinal tract, mediastinum, retroperitoneum, pelvis, trunk, extremities, head, neck, spleen, brain, pancreas, and liver. ${ }^{4}$

The etiologic factors responsible for development of IMT are not clearly established. Some investigators believe it is a true neoplasm, and the others believe that it represents an immunologic response to an infectious or noninfectious agent. ${ }^{1,5}$ But the etiology of the mechanism still remains unclear.

IMT is typically considered as benign lesion, but a spectrum including locally destructive variants is expectable. Biselli et al demonstrated that chromosomal aberrations may be present in IMT. ${ }^{6}$ Cessna et al describes abnormalities of chromosome 2 p23 with expression of p 80 and ALK1 in up to $40 \%$ of IMTs. ${ }^{7}$ These studies have added molecular credence to the clinical observation that there is a spectrum of aggressiveness among IMTs, and some may exhibit aggressive local behavior and rarely metastasis. Up to $71 \%$ are positive for ALK1, and approximately $50 \%$ have clone rearrangement involving the ALK locus on chromosome 2p23 that provides support for the neoplastic nature of IMT. The ALK gene encodes a receptor tyrosine kinase that has strong oncogenic activity when constitutively activated. ${ }^{7-9}$ However, as a predictor, ALK expression has not demonstrated a clear relationship with prognosis. On the one hand, ALK1-negative tumors occur in older patients and display greater nuclear pleomorphism and atypical mitoses; in two recent series, metastatic IMTs were confined to ALK1-negative lesions. ${ }^{8,10}$ Whereas on the other hand, positive ALK1 status may be more frequent in younger males and associated with a higher recurrence rate. ${ }^{11}$ In our young case, we were unable to demonstrate ALK cytogenetic analysis, ALK immunohistochemistry analysis was found negative and there was no atypia or recurrence.

Microscopically, IMT also shows a similarity to a gastrointestinal stromal tumor. An IMT consists of the proliferation of spindled to epithelioid myofibroblasts with admixed inflammatory cells, predominantly of mononuclear type. Tumor 
cells without atypia or hyperchromatism can invade the muscularis propria and even the adventitia. For final diagnosis of an IMT, immunohistochemistry analysis is very important. Tumor cells are characteristically positive for vimentin and do not express CD117 and CD34 in IMT., ${ }^{1,12}$ The cells are positive for smooth muscle actin (SMA) with or without desmin expression and S100 positivite. ${ }^{13}$ In our case, tumor cells were common positive for actin, negative for S100, ALK, and there was no desmin, CD117, CD34 expression.

Bonnet et al reported that IMT cases documented in the mesentery/omentum were in fact mostly located in the mesentery of the small bowel. ${ }^{14}$ Clinical presentation of IMT varies markedly, depending on the site at which the tumors originated. At the intestinal location, the onset may be insidious or rapid and may be accompanied by weight loss, malaise, a mass, and a variety of laboratory abnormalities. ${ }^{5}$ Childhood IMT cases with an intramural location of the tumor have interestingly presented with diarrhea and intestinal obstruction. ${ }^{15}$ Rarely, the presentation may be a complicated picture such as intestinal obstruction and intussusception. ${ }^{16,17}$ Colonic IMT is a rare condition in abdominal IMT and the most common site has been the right colon. Colonic IMT can be served as a lead point for intussusception. ${ }^{18,19}$ There are few pediatric cases of colonic IMT with intussusception in the literature.

The incidence of local recurrence has been reported to be 15 to $37 \%$ in large series of children presenting with IMT of mesentery and retroperitoneum. ${ }^{1}$ We evaluated our case through colonoscopy for this recurrence risk and no recurrence was detected in the colon.

Patients may have hypochromic microcytic anemia, thrombocytosis, polyclonal hyperglobulinemia, and elevated erythrocyte sedimentation rate in IMT. However, following a complete resection abnormal laboratory tests recover rapidly. ${ }^{20}$ Hyperglobulinemia was not observed in our case. She has hypochromic microcytic anemia, elevated erythrocyte sedimentation rate, and elevated platelet count. After surgery, all laboratory tests improved.

Surgical excision should be the primary therapy for cases with IMT. ${ }^{17}$ Complete resection is associated with less than $10 \%$ risk of local recurrence. We have performed surgical excision of the mass in our patient and no recurrence has occurred yet. Chemotherapy has been reserved for patients in whom resection is morbid, impossible or in patients who have incomplete resections. There is no evidence to prove that chemotherapy is effective when used singly, however, it may play a role following complete resection. There is little evidence within the literature regarding chemotherapy for IMT, and the majority of data are within the pediatric population. ${ }^{4}$ Radiation is typically reserved for palliation, to alleviate the mass effect of the IMT, or in conjunction with chemotherapy for cure in patients who are not suitable to resection. Radiation treatment has been shown to be of some benefit in pulmonary IMT. ${ }^{21}$ As with chemotherapy, there is currently no evidence to support routine use of radiotherapy in patients who have complete resection. Steroids may be added to reduce surrounding inflammation if deemed necessary, particularly in cases that involve the central nerves system. Nonsteroidal anti-inflammatory drugs (NSAIDs) have been successful in the treatment of IMTs when resectability is limited due to the tumor invading vital structures. ${ }^{22}$ Chemotherapy combined with oral NSAIDs may be an effective therapeutic option for patients with unresectable IMT. ${ }^{23}$

In conclusion, colonic IMT is a rare condition and intussusception is a rare complication of this tumor. Therefore, presentation of this case is very important for the literature. Because of recurrence risk the clinical and laboratory followup should be done in these cases.

\section{Conflict of Interest}

None.

\section{References}

1 Coffin CM, Watterson J, Priest JR, Dehner LP. Extrapulmonary inflammatory myofibroblastic tumor (inflammatory pseudotumor). A clinicopathologic and immunohistochemical study of 84 cases. Am J Surg Pathol 1995;19(8):859-872

2 Kim EY, Lee IK, Lee YS, et al. Inflammatory myofibroblastic tumor in colon. J Korean Surg Soc 2012;82(1):45-49

3 Narla LD, Newman B, Spottswood SS, Narla S, Kolli R. Inflammatory pseudotumor. Radiographics 2003;23(3):719-729

4 Karnak I, Senocak ME, Ciftci AO, et al. Inflammatory myofibroblastic tumor in children: diagnosis and treatment. J Pediatr Surg 2001;36(6):908-912

5 Hedlund GL, Navoy JF, Galliani CA, Johnson WH Jr. Aggressive manifestations of inflammatory pulmonary pseudotumor in children. Pediatr Radiol 1999;29(2):112-116

6 Biselli R, Boldrini R, Ferlini C, Boglino C, Inserra A, Bosman C. Myofibroblastic tumours: neoplasias with divergent behaviour. Ultrastructural and flow cytometric analysis. Pathol Res Pract 1999;195(9):619-632

7 Cessna MH, Zhou H, Sanger WG, et al. Expression of ALK1 and p80 in inflammatory myofibroblastic tumor and its mesenchymal mimics: a study of 135 cases. Mod Pathol 2002;15(9):931-938

8 Coffin CM, Hornick JL, Fletcher CD. Inflammatory myofibroblastic tumor: comparison of clinicopathologic, histologic, and immunohistochemical features including ALK expression in atypical and aggressive cases. Am J Surg Pathol 2007;31(4):509-520

9 Cook JR, Dehner LP, Collins MH, et al. Anaplastic lymphoma kinase (ALK) expression in the inflammatory myofibroblastic tumor: a comparative immunohistochemical study. Am J Surg Pathol 2001; 25(11):1364-1371

10 Mergan F, Jaubert F, Sauvat F, et al. Inflammatory myofibroblastic tumor in children: clinical review with anaplastic lymphoma kinase, Epstein-Barr virus, and human herpesvirus 8 detection analysis. J Pediatr Surg 2005;40(10):1581-1586

11 Alaggio R, Cecchetto G, Bisogno G, et al. Inflammatory myofibroblastic tumors in childhood: a report from the Italian Cooperative Group studies. Cancer 2010;116(1):216-226

12 Salameh M, Sultan I, Barbar M, et al. Inflammatory myofibroblastic tumor causing unexplained anemia in a toddler: a case report. J Med Case Reports 2011;5:69

13 Miettinen M, Sobin LH, Sarlomo-Rikala M. Immunohistochemical spectrum of GISTs at different sites and their differential diagnosis with a reference to CD117 (KIT). Mod Pathol 2000;13(10):1134-1142

14 Bonnet JP, Basset T, Dijoux D. Abdominal inflammatory myofibroblastic tumors in children: report of an appendiceal case and review of the literature. J Pediatr Surg 1996;31(9):1311-1314

15 Myint MA, Medeiros LJ, Sulaiman RA, Aswad BI, Glantz L. Inflammatory pseudotumor of the ileum. A report of a multifocal, transmural lesion with regional lymph node involvement. Arch Pathol Lab Med 1994;118(11):1138-1142 
16 Ciftci AO, Akçören Z, Tanyel FC, Senocak ME, Cağlar M, Hiçsönmez A. Inflammatory pseudotumor causing intestinal obstruction: diagnostic and therapeutic aspects. J Pediatr Surg 1998;33(12): 1843-1845

17 Saleem MI, Ben-Hamida MA, Barrett AM, et al. Lower abdominal inflammatory myofibroblastic tumor -an unusual presentation-a case report and brief literature review. Eur J Pediatr 2007;166(7): 679-683

18 Gupta RK, Samalavicius NE, Sapkota S, Sah PL, Kafle SU. Colonic inflammatory myofibroblastic tumours: an institutional review. Colorectal Dis 2013;15(5):e239-e243

19 Kovach SJ, Fischer AC, Katzman PJ, et al. Inflammatory myofibroblastic tumors. J Surg Oncol 2006;94(5):385-391
20 Souid AK, Ziemba MC, Dubansky AS, et al. Inflammatory myofibroblastic tumor in children. Cancer 1993;72(6):2042-2048

21 Imperato JP, Folkman J, Sagerman RH, Cassady JR. Treatment of plasma cell granuloma of the lung with radiation therapy. A report of two cases and a review of the literature. Cancer 1986;57(11): 2127-2129

22 Przkora R, Bolder U, Schwarz S, et al. Regression of nonresectable inflammatory myofibroblastic tumours after treatment with nonsteroidal anti-inflammatory drugs. Eur J Clin Invest 2004;34(4): 320-321

23 Tao YL, Wang ZJ, Han JG, Wei P. Inflammatory myofibroblastic tumor successfully treated with chemotherapy and nonsteroidals: a case report. World J Gastroenterol 2012;18(47):7100-7103 